CHRONIC OBSTRUCTIVE PULMONARY DISEASE

\title{
Polyunsaturated fatty acids improve exercise capacity in chronic obstructive pulmonary disease
}

\author{
R Broekhuizen, E F M Wouters, E C Creutzberg, C A P M Weling-Scheepers, A M W J Schols
}

Thorax 2005;60:376-382. doi: 10.1136/thx.2004.030858

See end of article for authors' affiliations

Correspondence to:

Dr R Broekhuizen,

Department of Respiratory

Medicine, University

Hospital Maastricht, P O

Box 5800, $6202 \mathrm{AZ}$

Maastricht, The

Netherlands;

r.broekhuizen@pul.

unimaas.nl

Received 30 June 2004

Accepted 2 March 2005
Background: Muscle wasting and decreased muscle oxidative capacity commonly occur in patients with chronic obstructive pulmonary disease (COPD). Polyunsaturated fatty acids (PUFA) have been shown to mediate several inflammatory and metabolic pathways which may be involved in the pathogenesis of muscle impairment in COPD. The aim of this study was to investigate the effect of PUFA modulation on systemic inflammation, reversal of muscle wasting, and functional status in COPD.

Methods: Eighty patients with COPD (57 men) with forced expiratory volume in 1 second $\left(\mathrm{FEV}_{1}\right) 37.3$ (13.8)\% predicted received $9 \mathrm{~g}$ PUFA or placebo daily in a double blind randomised fashion during an 8 week rehabilitation programme. Body composition (bioelectrical impedance), functional capacity (lung function, incremental cycle ergometry test, submaximal cycle test, isokinetic quadriceps strength) and inflammatory markers (C-reactive protein (CRP), interleukin (IL)- 6 and tumour necrosis factor (TNF)- $\alpha$ ) were assessed at baseline and after 8 weeks.

Results: Both groups had similar increases in weight, fat-free mass (FFM), and muscle strength. The peak load of the incremental exercise test increased more in the PUFA group than in the placebo group (difference in increase $9.7 \mathrm{~W}(95 \% \mathrm{Cl} 2.5$ to 17.0), $\mathrm{p}=0.009)$ even after adjustment for FFM. The duration of the constant work rate test also increased more in patients receiving PUFA (difference in increase $4.3 \mathrm{~min}(95 \% \mathrm{Cl} 0.6$ to 7.9$), p=0.023)$. The positive effects of PUFA could not be attributed to a decrease in systemic levels of CRP, IL- 6 and TNF- $\alpha$.

Conclusions: This is the first study to show beneficial effects of PUFA on exercise capacity in patients with COPD.
A t present the treatment of chronic obstructive pulmonary disease (COPD) is predominantly focused on primary organ dysfunction. However, COPD is increasingly emerging as a multiorgan systemic disease. Skeletal muscle weakness has been shown independently to aggravate important symptoms such as dyspnoea and impaired exercise performance.

Skeletal muscle performance is characterised by strength and endurance. Muscle wasting, which has been linked to enhanced systemic inflammation, ${ }^{2}$ is common in patients with COPD, adversely affecting muscle strength and exercise capacity. ${ }^{3}$ Independent of muscle wasting, intrinsic abnormalities in peripheral skeletal muscle morphology and metabolism have been described in COPD patients, pointing towards a decreased oxidative capacity. These abnormalities include muscle fibre type shifts from the oxidative type I fibres towards the glycolytic type IIx fibres ${ }^{4}$ and a decrease in oxidative enzymes involved in carbohydrate and fatty acid oxidation. ${ }^{5}$ The metabolic adaptations have clinical consequences as illustrated by a decreased mechanical efficiency ${ }^{6}$ and enhanced lactic acid production during cycling compared with healthy control subjects. ${ }^{7}$ In addition, nuclear magnetic resonance (NMR) studies using single limb exercise models showed a rapid decline and impaired recovery of phosphocreatine stores. ${ }^{8}$

Positive effects of pulmonary rehabilitation, particularly of endurance exercise training, illustrate that decreased muscle oxidative capacity in COPD is at least partially reversible. ${ }^{8}$ The available studies show that it is difficult to enhance this improvement by modulating exercise type and intensity only. ${ }^{9}$ It is therefore tempting to explore the potential of nutritional modulation on muscle substrate metabolism to enhance improvement of exercise capacity in COPD. Previous research in optimising rehabilitation with nutrition has led towards a combination of training with a protein and energy dense supplementation in cachectic COPD patients, increasing their fat-free mass (FFM) and muscle function. ${ }^{10}$ However, some patients, characterised by an increased systemic inflammatory response, did not respond sufficiently to this combination in treatment and, as a consequence, did not gain weight or FFM. ${ }^{11}$

Previous experimental research and clinical studies in other conditions indicate that the response to rehabilitation might be improved by polyunsaturated fatty acids (PUFA). ${ }^{12}{ }^{13}$ PUFA can modulate nuclear factor kappa $\mathrm{B}$ $(\mathrm{NF}-\mathrm{\kappa B}),{ }^{14}$ subsequently influencing local and systemic cytokine biology. NF- $\mathrm{KB}$ is a transcription factor that is activated in response to inflammatory cytokines in many cell types, including skeletal myocytes. A recent study provided evidence for NF- $\kappa \mathrm{B}$ activation in muscle biopsies of severely underweight COPD patients, ${ }^{15}$ making it a potential interesting target for modulation by PUFA. In addition, PUFA have been shown to upregulate (fat) oxidative gene expression by activation of peroxisome proliferator activated receptors (PPARs). ${ }^{16}$ The latter mechanism could explain the results of a recent study in cachectic patients with pancreatic cancer which found that PUFA supplementation increased physical activity level assessed by doubly labelled water. ${ }^{13}$

Abbreviations: $\mathrm{BMI}$, body mass index; $\mathrm{CRP}, \mathrm{C}$-reactive protein; $\mathrm{FEV}_{1}$, forced expiratory volume in 1 second; FFM, fat-free mass; FFMI, fat-free mass index; FM, fat mass; FVC, forced expiratory vital capacity; IL-6, interleukin 6; ITGV, intrathoracic gas volume; IVC, inspiratory vital capacity; $\mathrm{PaO}_{2}$, arterial oxygen pressure; $\mathrm{PaCO}_{2}$, arterial carbon dioxide pressure; PPAR, peroxisome proliferator activated receptor; PUFA, polyunsaturated fatty acids; RER, respiratory exchange ratio; RV, residual volume; TLCO, carbon monoxide transfer factor; TNF- $\alpha$, tumour necrosis factor $\alpha ; V_{C_{2}}$, peak carbon dioxide production; $V E$, peak ventilation; $\mathrm{VO}_{2}$, peak oxygen consumption 
The aim of the present study was to investigate the effect of PUFA supplementation on the outcome of pulmonary rehabilitation of COPD patients, firstly determined by functional performance and exercise capacity and, secondly, as determined by a reversal of muscle wasting in relation to chronic low grade inflammation.

\section{METHODS \\ Subjects}

The study population consisted of Dutch patients with clinically stable GOLD stage II-IV COPD consecutively admitted to an inpatient pulmonary rehabilitation centre (Asthma Center Hornerheide, Horn, The Netherlands) during the years 2000-2002. Patients were excluded if suffering from concurrent diseases such as malignancies, gastrointestinal or kidney abnormalities, metabolic or endocrine diseases, and inflammatory diseases. During rehabilitation patients received maintenance respiratory medication that in general consisted of inhaled bronchodilators, inhaled corticosteroids and, when indicated, theophyllines.

\section{Intervention}

The study design was placebo controlled, randomized, and double blind. During an 8 week training programme all patients received nine capsules daily, each capsule containing $1 \mathrm{~g}$ of either a blend of PUFA or placebo. The daily dosage of PUFA consisted of $3.4 \mathrm{~g}$ active fatty acids, a blend of $400 \mathrm{mg}$ stearidonic acid (STA, 18:4n-3), $760 \mathrm{mg}$ gamma-linoleinic acid (GLA, 18:3n-6), $1200 \mathrm{mg}$ alpha-linolenic acid (ALA, 18:3n-3), $700 \mathrm{mg}$ eicosapentanoic acid (EPA, 20:5n-3), and $340 \mathrm{mg}$ docosahexanoic acid (DHA, 22:6n-3). The placebo capsules contained $80 \%$ palm oil and $20 \%$ sunflower oil and had the same caloric content ( $9 \mathrm{kcal} /$ capsule) as the PUFA capsules. All capsules were enriched with $3.5 \mathrm{mg} / \mathrm{g}$ vitamin E to stabilise the oil and to serve as an antioxidant. The patients who were depleted or suffering from recent weight loss ( $\mathrm{n}=48,24$ in PUFA group and 24 in placebo group) also received $3 \times$ daily liquid nutritional supplements (Respifor ${ }^{\circledR}$ $375 \mathrm{ml}$ total) containing $3.4 \mathrm{~g}$ PUFA (2.85 g linoleic acid (LA: 18:2n-6) and $0.6 \mathrm{~g} \alpha$-linolenic acid (ALA: 18:3n-3)). Depletion was defined as a body mass index (BMI: body weight/height ${ }^{2}$ ) $\leqslant 21 \mathrm{~kg} / \mathrm{m}^{2}$ and/or fat-free mass index (FFMI: fat-free mass $/$ height $^{2}$ ) $\leqslant 16 \mathrm{~kg} / \mathrm{m}^{2}$ for male patients and $\leqslant 15 \mathrm{~kg} / \mathrm{m}^{2}$ for female patients. Capsules and drink supplements were given in between the regular meals under supervision of the staff of the inpatient rehabilitation centre. The physical exercise training programme, which was also blinded for PUFA intervention, consisted of a combination of supervised endurance and strength exercise training as described elsewhere. ${ }^{17}$

The ethical review board of the University Hospital Maastricht approved the study and all patients gave their written informed consent.

\section{Measurements \\ Pulmonary function}

Forced expiratory volume in 1 second $\left(\mathrm{FEV}_{1}\right)$ and forced vital capacity (FVC) were assessed from the flow-volume curve using a spirometer (Masterlab, Jaeger, Würzburg, Germany) at baseline. $\mathrm{FEV}_{1}$ was also assessed 15 min after inhalation of $\beta$ agonists via a metered dose inhaler. Carbon monoxide transfer factor (TLCO) was determined using the single breath method (Masterlab). Lung functional parameters were expressed as a percentage of reference values. ${ }^{18}$ Blood was drawn from the brachial artery to analyse arterial oxygen tension $\left(\mathrm{PaO}_{2}\right)$ and carbon dioxide tension $\left(\mathrm{PaCO}_{2}\right)$ with a blood gas analyser (Radiometer, ABL 330, Copenhagen, Denmark).

\section{Body composition}

At baseline and after 8 weeks BMI was calculated as weight divided by height in squared metres $\left(\mathrm{kg} / \mathrm{m}^{2}\right)$. Fat-free mass (FFM; kg) was measured using single frequency $(50 \mathrm{kHz})$ bioelectrical impedance analysis (BIA; Xitron Technologies, San Diego, CA, USA) with subjects in the supine position. FFM of patients was calculated using the disease-specific equation proposed by Schols and described by Steiner et al. ${ }^{19}$ Fat-free mass index (FFMI) was calculated as FFM divided by height ${ }^{2}\left(\mathrm{~kg} / \mathrm{m}^{2}\right)$.

\section{Blood sampling}

Fasting blood was collected in evacuated blood collecting tubes containing EDTA (Becton Dickinson Vacutainer Systems, Plymouth, UK) in the early morning (08.0010.00 hours) at baseline and after 8 weeks. After centrifuging twice at $1000 \mathrm{~g}$ for 10 minutes at $4^{\circ} \mathrm{C}$ within 2 hours of collection, plasma samples were stored at $-70^{\circ} \mathrm{C}$ until analysis. Interleukin (IL) -6 and tumour necrosis factor (TNF)- $\alpha$ were determined with the Quantikine high sensitivity ELISA (R\&D Systems, Minneapolis, USA) with a lower detection limit of $0.039 \mathrm{pg} / \mathrm{ml}$ for IL-6 and $0.5 \mathrm{pg} / \mathrm{ml}$ for total TNF- $\alpha$. C-reactive protein (CRP) was assessed by high sensitivity particle enhanced immunonephelometry (NHs CRP, Dade Behring). The lower detection limit was $0.159 \mathrm{mg} / \mathrm{l}$. A CRP concentration higher than the cut off point of $5 \mathrm{mg} / \mathrm{l}$, as used by many clinical laboratories, was regarded as raised.

\section{Exercise capacity}

\section{Incremental bicycle ergometry test}

An incremental bicycle ergometry test was performed on an electromagnetic braked ergometer (Corival 400, Lode, Groningen, The Netherlands) under supervision of a chest physician to investigate maximal leg exercise capacity. After 2 minutes of resting and 1 minute unloaded cycling, power was increased every minute by $10 \mathrm{~W}$. In a subgroup of patients not suffering from chronic hypoxia (PUFA $\mathrm{n}=32$; placebo $\mathrm{n}=33 ; \mathrm{PaO}_{2} \geqslant 7.3 \mathrm{kPa}$ ), peak oxygen consumption $\left(\mathrm{VO}_{2}\right)$, peak carbon dioxide production $\left(\mathrm{VCO}_{2}\right)$ and peak ventilation $(\mathrm{VE})$ were also measured and calculated from breath by breath analysis using a breathing mask (Oxycon Beta, Jaeger, Würzburg, Germany). The respiratory exchange ratio (RER) was calculated as $\mathrm{VCO}_{2} / \mathrm{VO}_{2}$. Baseline peak workload used in the analysis was expressed as a percentage of reference values. ${ }^{20}$

\section{Submaximal bicycle ergometry test}

The patients performed a submaximal bicycle test of 2 minutes unloaded cycling, 10 minutes at 50\%, followed by a maximum of 20 minutes at $70 \%$ of individually measured peak workload of the incremental bicycle ergometry test performed on an electromagnetic braked ergometer (Corival 400, Lode, Groningen, The Netherlands). Endurance time, defined as the time of cycling, was measured.

\section{Skeletal muscle strength}

Isokinetic quadriceps strength of the dominant leg of the patients was measured using a Biodex dynamometer (Biodex Corporation, Shirley, USA) following the protocol described by Gosker et al. ${ }^{21}$ In order to avoid learning effects, all subjects practised on the dynamometer under supervision of a physiotherapist the day before the actual test.

Skeletal muscle function of the upper extremities was assessed with use of a Harpenden handgrip dynamometer (Yamar, Preston, Jackson, MI, USA). The mean of the highest of three attempts per hand was used in the analysis. 


\section{Respiratory muscle function}

Respiratory muscle function was assessed by measuring maximal inspiratory mouth pressure (Pimax) according to the method of Black and Hyatt. ${ }^{22}$ The best of three attempts was taken for analysis. Pimax values were noted as positive values.

\section{Data handling and statistical analysis}

Results are presented as mean (95\% confidence interval) for all variables that were normally distributed. Differences between the groups at baseline were analysed by the Student's $t$ test for independent samples. The outcome of the variables after 8 weeks of intervention were compared between groups by linear regression with baseline value of the parameter, intervention with PUFA, and intervention with drink supplements as predictors. There was no interaction between PUFA intervention and intervention with drink supplements. Normally distributed parameters within groups were compared with the paired Student's $t$ test. Data were analysed using Statistical Package for Social Sciences (SPSS) Version 10.1 for Windows (SPSS Inc, Chicago, IL, USA). Statistical significance was assumed at a p value of 0.05 .

\section{RESULTS}

\section{Participants}

Four hundred and twenty nine patients were admitted to the rehabilitation centre during the study period which lasted from July 2000 until October 2002; 258 did not meet the inclusion criteria and 69 patients did not want to participate. The intent-to-treat group therefore consisted of 102 patients (71 men and 31 women; 51 PUFA and 51 placebo). Three patients in the placebo group had to discontinue the study because of admission to hospital due to exacerbation $(\mathrm{n}=2)$ or pneumothorax $(n=1)$. One patient in the PUFA group discontinued the intervention due to enteric fever. Four patients (PUFA: $n=2$, placebo: $n=2$ ) resigned from the rehabilitation centre because of personal problems and four patients (PUFA: $\mathrm{n}=3$, placebo: $\mathrm{n}=1$ ) were not willing to cooperate further with the study. In the placebo group, three patients discontinued because of an increase in complaints such as belching and nausea, while in the PUFA group seven patients discontinued the study due to belching, nausea, vomiting, fishy taste in the mouth, and stomach ache. In total, nine patients in the placebo group and 13 in the PUFA group discontinued the intervention, leaving 80 patients to complete the study (PUFA: $n=38$, placebo: $n=42$; fig 1 ). There was no significant difference either in the number of patients dropping out of the study or in those with complaints due to the intervention between the PUFA and the placebo groups.

\section{Baseline characteristics}

The baseline characteristics of both groups in the intent-totreat group of patients are shown in table 1. The patients were characterised by low BMI and low FFMI. In addition, these patients were compromised in exercise capacity as their peak load was $41.2(19.3) \%$ of predicted. CRP, as a marker of systemic inflammation, was increased (176.1 (252.3)\% of $5 \mathrm{mg} / \mathrm{l}$ ). No significant differences were found between baseline characteristics of the PUFA group and the placebo group. The patients who discontinued the study did not differ from the per-protocol group on all parameters, except for having a shorter duration time on the submaximal cycle ergometry test (drop out group: 7.2 (4.4) min; per-protocol group: 13.0 (7.7) $\mathrm{min}, \mathrm{p}=0.01$ ).

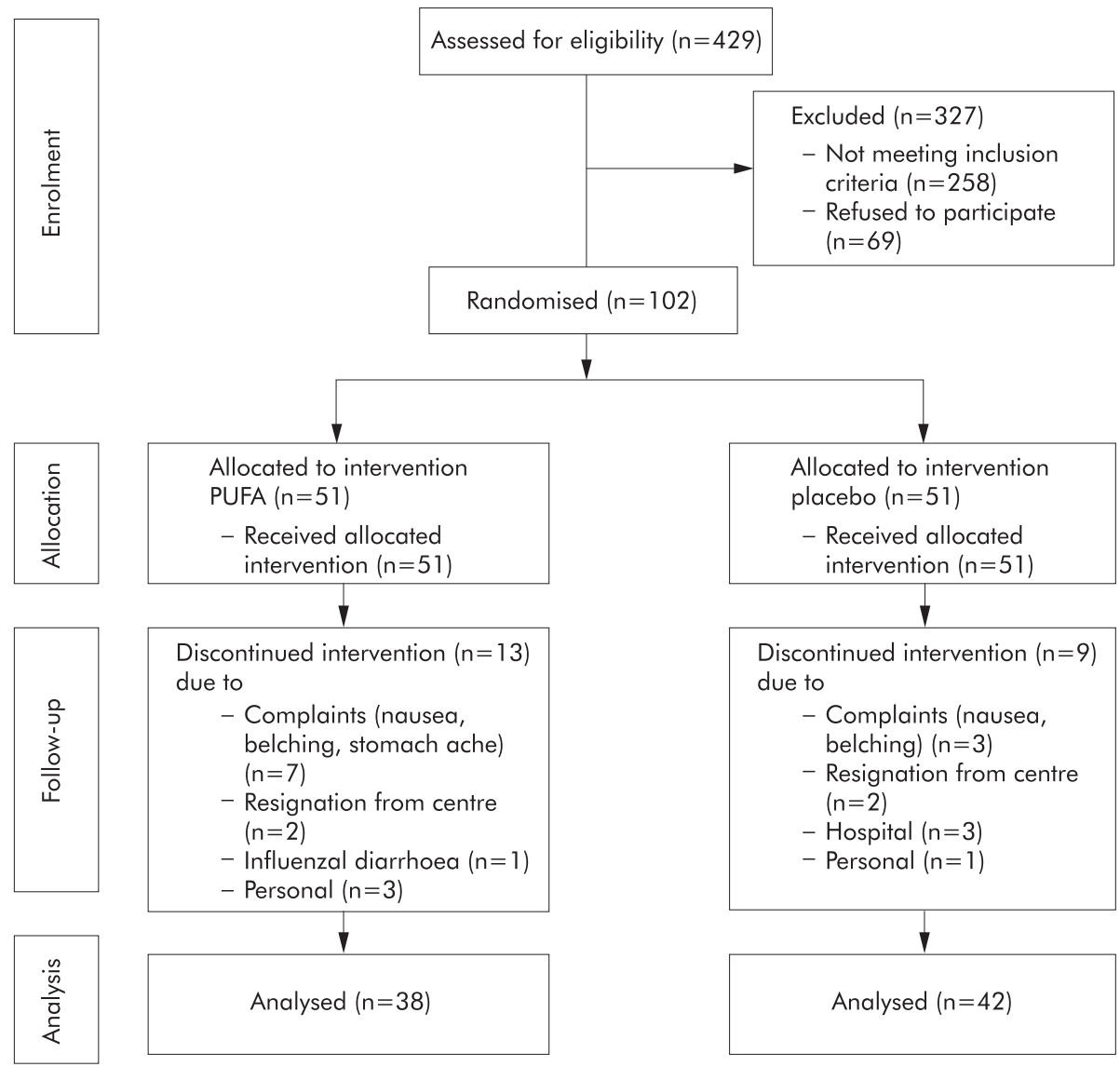

Figure 1 Patient flow diagram. 


\begin{tabular}{|c|c|c|}
\hline & $\begin{array}{l}\text { PUFA } \\
(n=51)\end{array}$ & $\begin{array}{l}\text { Placebo } \\
(\mathrm{n}=51)\end{array}$ \\
\hline$M / F$ & $36 / 15$ & $35 / 16$ \\
\hline Age (years) & $64(10)$ & $62(8)$ \\
\hline Height $(\mathrm{m})$ & $1.70(0.07)$ & $1.70(0.07)$ \\
\hline BMI $\left(\mathrm{kg} / \mathrm{m}^{2}\right)$ & $22.5(4.0)$ & $22.1(3.6)$ \\
\hline FFMI $\left(\mathrm{kg} / \mathrm{m}^{2}\right)$ & $16.1(2.1)$ & $15.7(1.8)$ \\
\hline FM (\%) & 27.5 (7.2) & $28.3(7.1)$ \\
\hline $\begin{array}{l}\text { Smoking history } \\
\text { (pack years) }\end{array}$ & $38(26)$ & 34 (19) \\
\hline $\mathrm{FEV}_{1}(\%$ predicted) & $38.2(13.1)$ & $35.8(15.1)$ \\
\hline Reversibility (\%) & $1.9(5.7)$ & $2.0(4.0)$ \\
\hline FVC (\% predicted) & $77.6(16.3)$ & $75.9(20.1)$ \\
\hline IVC (\% predicted) & 77.8 (16.5) & $78.8(19.1)$ \\
\hline RV (\% predicted) & $195.6(57.2)$ & $192.6(55.0)$ \\
\hline ITGV (\% predicted) & $161.7(34.2)$ & $162.4(37.4)$ \\
\hline TLCO (\% predicted) & $52.1(20.4)$ & 46.4 (19.3) \\
\hline $\mathrm{PaO}_{2}(\mathrm{kPa})$ & $9.2(1.3)$ & $9.3(1.1)$ \\
\hline $\mathrm{PaCO}_{2}(\mathrm{kPa})$ & $5.5(0.9)$ & $5.3(0.7)$ \\
\hline $\begin{array}{l}\text { Peak load incremental test } \\
\text { (\% predicted) }\end{array}$ & $39.6(18.3)$ & $42.9(20.3)$ \\
\hline CRP (\% increase) & $188(272)$ & $165(233)$ \\
\hline
\end{tabular}

BMI, body mass index; FFMI, fat-free mass index; FM, fat mass; FEV forced expiratory volume in 1 second; FVC, forced expiratory vital capacity; IVC, inspiratory vital capacity; RV, residual volume; ITGV, intrathoracic gas volume; TLCO, carbon monoxide transfer factor; $\mathrm{PaO}_{2}$, arterial oxygen pressure; $\mathrm{PaCO}_{2}$, arterial carbon dioxide pressure; CRP, C-reactive protein.

Variables were compared between groups by the Student's $t$ test for independent samples. There were no significant differences between groups $(p>0.05)$.

\section{PUFA intervention}

\section{Exercise capacity}

Figure 2 shows the results of the PUFA intervention on exercise capacity. The maximum load increased during the incremental maximal bicycle ergometry test in both the intervention and placebo groups. In the PUFA group, however, the maximum load increased significantly more after 8 weeks of intervention (difference in change in maximum load $9.7 \mathrm{~W}$ (95\% CI 2.5 to 17.0$), p=0.009$; fig 2A), even when corrected for FFM (difference in change in maximum load corrected for FFM $0.209 \mathrm{~W} / \mathrm{kg}$ (95\% CI 0.054 to 0.364$), p=0.009$ ). In a subgroup of patients not using long term oxygen therapy (LTOT; $\mathrm{n}=31$ in the PUFA group and $n=32$ in the placebo group), ventilatory and metabolic data were obtained during the maximal bicycle test (table 2). In both intervention groups $\mathrm{VO}_{2}$ and $\mathrm{VCO}_{2}$ were similarly increased at 8 weeks compared with baseline. However, RER tended to be increased by PUFA (mean difference 0.039 (95\% CI -0.001 to 0.078$), p=0.054)$. In addition, $\mathrm{VO}_{2}$ per load was significantly decreased, while in the placebo group neither variable changed.

Besides an improvement in maximal exercise capacity, the duration of the submaximal bicycle ergometry test improved in both intervention groups but, again, a greater increase was seen in the PUFA group (difference in change in duration $4.3 \min (95 \%$ CI 0.6 to 7.9 ), $\mathrm{p}=0.023$; fig $2 \mathrm{~B}$ ).

Body composition and peripheral muscle strength Body weight and FFM increased during the 8 week rehabilitation programme in both the PUFA and placebo groups, while FM only increased significantly in the PUFA group (table 3). Changes in weight and body composition were similar in both groups, however. In addition, within the group of depleted patients $(n=36,23 \mathrm{M} / 13 \mathrm{~F}, 19$ PUFA $/ 17$ placebo) who were receiving nutritional supplementation, no differences in change of body composition or response were seen between those receiving PUFA or placebo (data not
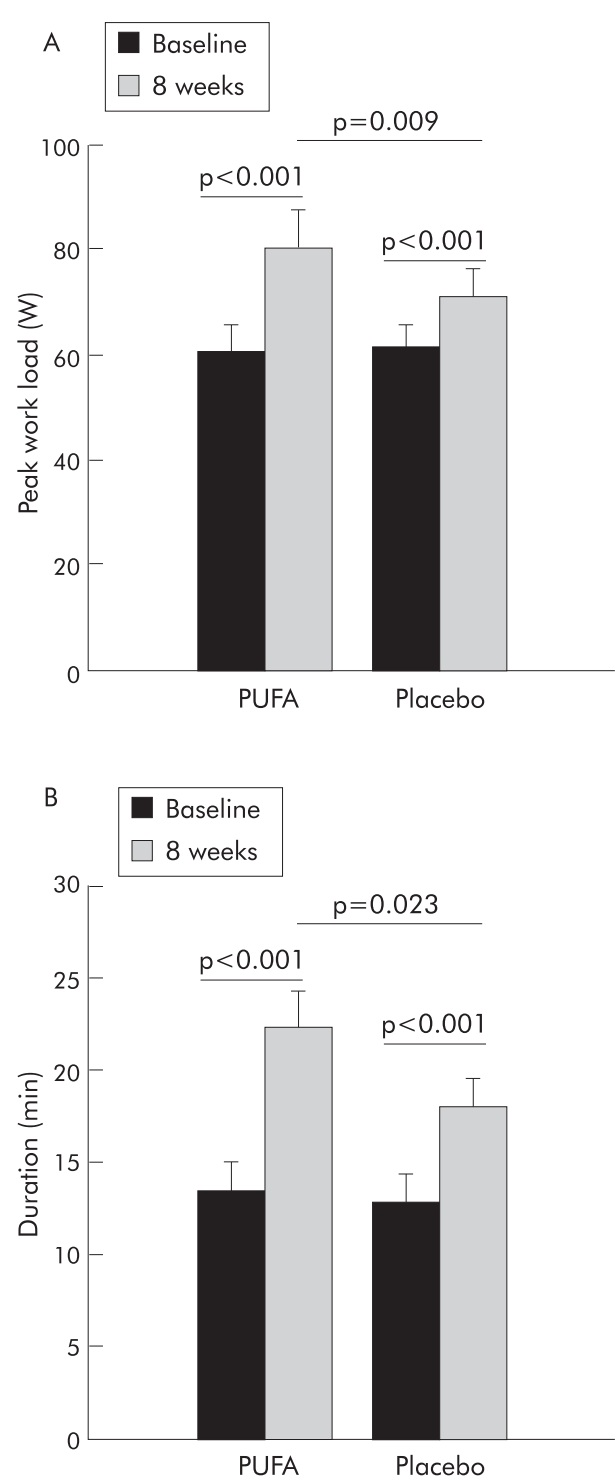

Figure 2 (A) Peak workload. The increase in peak workload during the incremental bicycle ergometry test was higher in patients receiving PUFA than in patients receiving placebo during an 8 week rehabilitation programme (mean difference $9.7 \mathrm{~W}(95 \% \mathrm{Cl} 2.5$ to 17.0$), p=0.009)$. (B) Duration. The increase in duration of the submaximal bicycle ergometry test was higher in patients receiving PUFA than in patients receiving placebo during an 8 week rehabilitation programme (mean difference $4.3 \mathrm{~min}(95 \% \mathrm{Cl} 0.6$ to 7.9$) ; p=0.023)$. Data are presented as mean (SE). Within group changes were tested with the paired $t$ test between groups by linear regression $(p<0.05)$.

shown). No complementary effect of PUFA on FFM was therefore seen in addition to protein energy supplementation.

In line with the changes in FFM, quadriceps muscle strength increased similarly in both intervention groups. No effect of the PUFA intervention was seen in strength parameters in addition to rehabilitation.

\section{Systemic inflammation}

CRP, IL-6, and TNF- $\alpha$ did not change after rehabilitation or after PUFA intervention (fig 3 ).

\section{Lung function}

PUFA intervention had no effect on $\mathrm{FEV}_{1}$ and inspiratory muscle strength (data not shown). 
Table 2 Difference in functional and ventilatory parameters of the maximal bicycle ergometry test before and after PUFA or placebo intervention during an 8 week rehabilitation programme

\begin{tabular}{lllll}
\hline & $\begin{array}{l}\text { PUFAt }(\mathbf{n}=37) \\
\text { Mean (SD) }\end{array}$ & $\begin{array}{l}\text { Placebot }(\mathbf{n}=38) \\
\text { Mean (SD) }\end{array}$ & $\begin{array}{l}\text { PUFA versus placeboł } \\
\text { Mean }(95 \% \mathrm{Cl})\end{array}$ & p value \\
\hline Peak load (W) & $19.7(20.2)^{*}$ & $10.0(13.6)^{*}$ & $9.7(2.5$ to 17.0$)$ & 0.009 \\
Load/FFM (W/kg) & $0.368(0.383)^{*}$ & $0.163(0.292)^{*}$ & $0.209(0.06$ to 0.37$)$ & 0.006 \\
Peak VO $(\mathrm{ml} / \mathrm{min})$ & $119(219)^{*}$ & $146(179)^{*}$ & $-23(-122$ to 77$)$ & 0.648 \\
Peak VCO $(\mathrm{ml} / \mathrm{min})$ & $172(277)^{*}$ & $128(207)^{*}$ & $35(-89$ to 158$)$ & 0.578 \\
RER & $0.033(0.096)^{*}$ & $-0.009(0.081)$ & $0.039(-0.001$ to 0.078$)$ & 0.054 \\
Peak VE $(1 / \mathrm{min})$ & $5.5(7.4)^{*}$ & $3.4(7.7)^{*}$ & $2.1(-1.8$ to 5.9$)$ & 0.290 \\
$\mathrm{VE}_{\mathrm{E} / \mathrm{VO}}$ & $0.276(6.004)$ & $-1.733(3.924)^{*}$ & $2.1(-0.451$ to 4.586$)$ & 0.106 \\
$\mathrm{VO}_{2} /$ load & $-1.396(3.444)^{*}$ & $-0.571(5.253)$ & $-1.028(-2.808$ to 0.752$)$ & 0.252 \\
\hline
\end{tabular}

FFM, fat-free mass; $\mathrm{VE}$, peak ventilation; $\mathrm{V}_{\mathrm{CO}_{2}}$, peak carbon dioxide production; $\mathrm{VO}_{2}$, peak oxygen consumption; RER, respiratory exchange ratio.

† Variables before and after intervention were compared within groups by the paired Student's $t$ test, ${ }^{*} \mathrm{p}<0.05$. †The change in outcome of the variables after 8 weeks of intervention were compared between groups by linear regression with baseline value of the parameter, intervention with PUFA, and intervention with drink supplements as predictors $(p<0.05)$. Values represent adjusted means with $95 \%$ confidence intervals.

\section{DISCUSSION}

This is the first study to show beneficial effects of PUFA on the response to exercise training in patients with COPD. The major new finding of this study was that, in addition to the beneficial effects of pulmonary rehabilitation, functional capacity in patients with COPD was increased after 8 weeks of PUFA supplementation compared with placebo as shown by improvements in peak exercise capacity and submaximal endurance time.

Previous epidemiological research has shown that PUFA intake has a protective effect on the development of COPD, decreasing risk dose dependently and increasing lung function in smokers. ${ }^{23}$ In this intervention study, which included patients with moderate to severe COPD, we did not find an increase in lung function after PUFA treatment. Health gain in these patients suffering from irreversible airflow obstruction is, however, more likely to be found in improvements in skeletal muscle function and exercise capacity. Peak work load and endurance time during submaximal cycle ergometry increased significantly more in the PUFA group than in the placebo group. This improvement could not be explained by an increase in muscle mass as peak load corrected for FFM increased more in the PUFA group than in the control group. However, PUFA supplementation increased RER which indicates that these patients could go deeper into anaerobic metabolism after rehabilitation than patients receiving placebo. Furthermore, mechanical efficiency (as measured by the difference in ratio of $\mathrm{VO}_{2}$ to peak work load) was improved in the PUFA group but remained unchanged in the placebo group. This may suggest improved muscle oxidative metabolism after PUFA intervention. Interestingly, and in line with this hypothesis, Moses et al ${ }^{13}$ showed that PUFA enriched food supplements increased the physical activity level and total daily energy expenditure in cachectic patients with pancreatic cancer. Barber et al ${ }^{24}$ have also shown an improvement in performance status (using the Karnofsky score) after PUFA supplementation in patients with pancreatic cancer. These changes could reflect modulatory effects of PUFA on muscle metabolism. Further studies are indicated using nuclear magnetic resonance spectroscopy and metabolic markers in muscle biopsies to test this hypothesis.

PUFA are known PPAR activators. ${ }^{25}$ The PPARs have been shown to promote the uptake of circulating fatty acids by cells through upregulation of the lipoprotein lipase gene. ${ }^{26}$ In addition, PPARs control mitochondrial fatty acid import and $\beta$-oxidation. ${ }^{27}$ It is possible that the increase in exercise capacity induced by PUFA seen in this study could be attributed to a PUFA-induced activation of PPAR, increasing fatty acid availability and oxidation. This possible increase in oxidative capacity might be related to changes in fibre types. Indeed, research has consistently shown a shift from the oxidative type I and type IIa fibres to the glycolytic type IIx fibres in COPD patients compared with controls. ${ }^{4}$ An increase in oxidative capacity could increase muscle endurance by sparing glycogen and delaying lactic acid production and the lactic acid threshold. In patients with COPD muscle glycogen is decreased compared with healthy controls, ${ }^{28}$ although this could be partly a reflection of inactivity. ${ }^{29}$ In addition, early lactic acidosis in response to exercise is common in $\mathrm{COPD}^{29}$ which can, at least partially, be reversed by training. ${ }^{30}$

Another possible PPAR mediated mechanism involves the chronic inflammation in the lungs of patients with COPD. Recent research has shown that, locally, PPAR expressed by

Table 3 Difference in body composition and peripheral muscle function before and after PUFA or placebo intervention during an 8 week rehabilitation programme

\begin{tabular}{lllll}
\hline & $\begin{array}{l}\text { PUFAt }(\mathbf{n}=38) \\
\text { Mean (SD) }\end{array}$ & $\begin{array}{l}\text { Placebot }(\mathbf{n}=42) \\
\text { Mean (SD) }\end{array}$ & $\begin{array}{l}\text { PUFA versus placeboł } \\
\text { Mean }(95 \% \mathrm{Cl})\end{array}$ & p value \\
\hline M/F & $27 / 11$ & $30 / 12$ & & \\
Weight (kg) & $2.0(2.3)^{*}$ & $1.6(2.7)^{*}$ & $0.4(-0.6$ to 1.4$)$ & 0.414 \\
FFM (kg) & $1.2(2.2)^{*}$ & $1.1(2.1)^{*}$ & $0.1(-0.8$ to 1.1$)$ & 0.821 \\
FM (kg) & $0.8(1.9)^{*}$ & $0.5(1.8)$ & $0.2(-0.5$ to 0.9$)$ & 0.573 \\
Quadriceps strength & $9(21)^{*}$ & $12(24)^{*}$ & $-4(-15$ to 7$)$ & 0.510 \\
$(\mathrm{Nm})$ & & & & \\
\hline
\end{tabular}

FFM, fat-free mass; FM, fat mass.

†Variables were compared within groups by the paired Student's $t$ test $\left({ }^{*} \mathrm{p}<0.05\right)$.

†The outcome of the variables after 8 weeks of intervention were compared between groups by linear regression with baseline value of the parameter, intervention with PUFA and intervention with drink supplements as predictors $(p<0.05)$. 


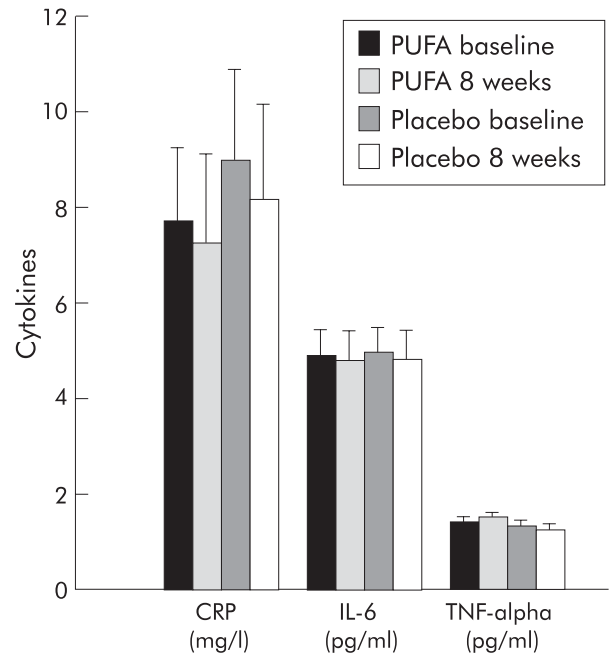

Figure 3 Inflammatory markers. No changes were seen in C-reactive protein (CRP), interleukin-6 (IL-6), or tumour necrosis factor- $\alpha$ (TNF- $\alpha$ ) after 8 weeks of either PUFA or placebo in combination with rehabilitation. Data are presented as mean (SE) change. Within group changes were tested with the paired $t$ test, between groups by linear regression $(p<0.05)$.

alveolar macrophages may play an anti-inflammatory role through inhibition of cytokine production and enhancement of phagocytosis. ${ }^{31}$ The anti-inflammatory response of PPAR was shown to be increased by PPAR activators. Although in the present study $\mathrm{FEV}_{1}$ did not seem to improve, a PUFAinduced decrease in local inflammation cannot be excluded. Further research is needed to elucidate the mechanism behind the improved exercise capacity after PUFA intervention, using more invasive techniques to assess local inflammatory and modulatory markers such as NFкB in the lungs (for example, induced sputum or bronchial biopsies) and muscle (muscle biopsies).

The second aim of this study was to investigate the effects of PUFA on body composition in relation to low grade systemic inflammation. The rationale for this hypothesis comes from previous positive results of PUFA modulation in other chronic inflammatory conditions such as rheumatoid arthritis and cancer cachexia. In patients with pancreatic cancer, preliminary uncontrolled studies have suggested that supplementation with fish oil or eicosapentanoic acid (EPA) reverses weight loss and decreases the acute phase response. ${ }^{32}$ However, these results were not confirmed in a recent multicentre double blind trial in which a higher dose of EPA supplementation was used..$^{33}$ The interaction of PUFA and cytokine biology is, however, complex since it has been shown that the ability of healthy volunteers to downregulate TNF- $\alpha$ production after PUFA intervention was associated with baseline TNF- $\alpha$ production and with TNF- $\alpha-308$ and lymphotoxin-a +252 polymorphisms. ${ }^{34}$

In this study patients in the PUFA and placebo groups showed a similar increase in body weight and FFM. These improvements in body composition are therefore the result of the rehabilitation programme including protein energy supplementation if indicated. It is probably not related to a decreased systemic inflammatory response as we did not find an effect of PUFA on the specific markers CRP, IL-6, and TNF- $\alpha$. Surprisingly, in this study only a few patients $(n=5)$ gained less than $2 \%$ in weight, which is used as an indication of non-response as defined by Creutzberg et al. ${ }^{11}$ This could be due to the use of smaller portions of drink supplements, attenuating the fall in habitual food intake. ${ }^{35}$ Interestingly, the patients who did not respond adequately had a higher
TNF- $\alpha$ level than those who did gain sufficient weight (data not shown). This is in agreement with the observations of Creutzberg et al who associated an increased systemic inflammation with non-response to nutritional therapy.

The fact that we did see a PUFA-induced increase in exercise capacity suggests that the PUFA blend used was sufficient in dosage and composition. In addition, it indicates that the intervention was long enough to cause an effect. Further research is needed to study dose-dependent mechanisms and the effects of other PUFA blends with different fatty acid compositions or other ratios of fatty acids. In addition, it remains to be investigated whether PUFA supplementation alone, without exercise training, will have a similar effect on exercise capacity in patients with COPD.

Although the nutritional supplementation with Respifor also contained PUFA, a possible synergistic effect has been separated from the PUFA effect as nutritional supplementation was also included in the statistical analysis as a predictor. In addition, there was no interaction between PUFA and the use of Respifor and the same number of depleted patients in the PUFA and the placebo group were included.

In conclusion, we have shown that PUFA modulation in combination with rehabilitation enhances the increase in exercise capacity in COPD which cannot be ascribed to changes in systemic inflammatory response.

\section{Authors' affiliations}

R Broekhuizen, E F M Wouters, A M W J Schols, Department of Respiratory Medicine, University Hospital Maastricht, Maastricht, The Netherlands

E C Creutzberg, C A P M Weling-Scheepers, Asthma Center Hornerheide, Horn, The Netherlands

This study was supported by Numico Research BV, The Netherlands

Conflict of interest: AMWJS has received funds for research from Numico Research BV. RB, ECC, CAPMW and EFMW have no competing interests to declare.

\section{REFERENCES}

1 Hamilton AL, Killian KJ, Summers E, et al. Muscle strength, symptom intensity, and exercise capacity in patients with cardiorespiratory disorders. Am J Respir Crit Care Med 1995;152:2021-31

2 Di Francia M, Barbier D, Mege JL, et al. Tumor necrosis factor-alpha levels and weight loss in chronic obstructive pulmonary disease. Am J Respir Crit Care Med 1994;150:1453-5.

3 Baarends EM, Schols AM, Mostert R, et al. Peak exercise response in relation to tissue depletion in patients with chronic obstructive pulmonary disease. Eur Respir J 1997; 10:2807-13.

4 Gosker HR, van Mameren H, van Dijk PJ, et al. Skeletal muscle fibre-type shifting and metabolic profile in patients with chronic obstructive pulmonary disease. Eur Respir J 2002;19:617-25.

5 Maltais $F$, LeBlanc $P$, Whittom $F$, et al. Oxidative enzyme activities of the vastus lateralis muscle and the functional status in patients with COPD. Thorax 2000;55:848-53.

6 Baarends EM, Schols AM, Akkermans MA, et al. Decreased mechanical efficiency in clinically stable patients with COPD. Thorax 1997;52:981-6.

7 Maltais F, Simard AA, Simard C, et al. Oxidative capacity of the skeletal muscle and lactic acid kinetics during exercise in normal subjects and in patients with COPD. Am J Respir Crit Care Med 1996;153:288-93.

8 Sala E, Roca J, Marrades RM, et al. Effects of endurance training on skeletal muscle bioenergetics in chronic obstructive pulmonary disease. Am J Respir Crit Care Med 1999;159:1726-34

9 Ortega F, Toral J, Cejudo P, et al. Comparison of effects of strength and endurance training in patients with chronic obstructive pulmonary disease. Am J Respir Crit Care Med 2002;166:669-74.

10 Schols AM, Soeters PB, Mostert R, et al. Physiologic effects of nutritional support and anabolic steroids in patients with chronic obstructive pulmonary disease. A placebo- controlled randomized trial. Am J Respir Crit Care Med 1995; 152:1268-74.

11 Creutzberg EC, Schols AM, Weling-Scheepers CA, et al. Characterization of nonresponse to high caloric oral nutritional therapy in depleted patients with chronic obstructive pulmonary disease. Am J Respir Crit Care Med 2000;161:745-52

12 Aguilaniu B, Flore P, Perrault $\mathrm{H}$, et al. Exercise-induced hypoxaemia in master athletes: effects of a polyunsaturated fatty acid diet. Eur J Appl Physiol Occup Physiol 1995;72:44-50. 
13 Moses AW, Slater C, Preston T, et al. Reduced total energy expenditure and physical activity in cachectic patients with pancreatic cancer can be modulated by an energy and protein dense oral supplement enriched with n-3 fatty acids. Br J Cancer 2004:90:996-1002.

14 Komatsu W, Ishihara K, Murata M, et al. Docosahexaenoic acid suppresses nitric oxide production and inducible nitric oxide synthase expression in interferon-gamma plus lipopolysaccharide-stimulated murine macrophages by inhibiting the oxidative stress. Free Radic Biol Med 2003;34:1006-16.

15 Agusti A, Morla M, Sauleda J, et al. NF-kappaB activation and iNOS upregulation in skeletal muscle of patients with COPD and low body weight. Thorax 2004;59:483-7.

16 Schoonjans K, Staels B, Auwerx J. The peroxisome proliferator activated receptors (PPARS) and their effects on lipid metabolism and adipocyte differentiation. Biochim Biophys Acta 1996;1302:93-109.

17 Creutzberg EC, Wouters EF, Mostert R, et al. Efficacy of nutritional supplementation therapy in depleted patients with chronic obstructive pulmonary disease. Nutrition 2003;19:120-7.

18 Quanjer PH. Standardized lung function testing. Official statement of the European Respiratory Society. Eur Respir J 1993:6(Suppl16):1-100.

19 Steiner MC, Barton RL, Singh SJ, et al. Bedside methods versus dual energy Xray absorptiometry for body composition measurement in COPD. Eur Respir J 2002; 19:626-31.

20 Jones NL, Summers E, Killian KJ. Influence of age and stature on exercise capacity during incremental cycle ergometry in men and women. Am Rev Respir Dis 1989;140:1373-80.

21 Gosker HR, Lencer NH, Franssen FM, et al. Striking similarities in systemic factors contributing to decreased exercise capacity in patients with severe chronic heart failure or COPD. Chest 2003;123:1416-24.

22 Black LF, Hyatt RE. Maximal respiratory pressures: normal values and relationship to age and sex. Am Rev Respir Dis 1969;99:696-702.

23 Shahar E, Folsom AR, Melnick SL, et al. Dietary n-3 polyunsaturated fatty acids and smoking-related chronic obstructive pulmonary disease. Atherosclerosis Risk in Communities Study Investigators. N Engl J Med 1994;331:228-33.

24 Barber MD, Ross JA, Voss AC, et al. The effect of an oral nutritional supplement enriched with fish oil on weight-loss in patients with pancreatic cancer. Br J Cancer 1999;81:80-6.
25 Keller H, Dreyer C, Medin J, et al. Fatty acids and retinoids control lipid metabolism through activation of peroxisome proliferator-activated receptorretinoid X receptor heterodimers. Proc Natl Acad Sci USA 1993;90:2160-4.

26 Schoonjans K, Peinado-Onsurbe J, Lefebvre AM, et al. PPARalpha and PPARgamma activators direct a distinct tissue-specific transcriptional response via a PPRE in the lipoprotein lipase gene. EMBO J 1996;15:5336-48.

27 Gulick T, Cresci S, Caira T, et al. The peroxisome proliferator-activated receptor regulates mitochondrial fatty acid oxidative enzyme gene expression. Proc Natl Acad Sci USA 1994;91:11012-6.

28 Jakobsson $\mathrm{P}$, Jorfeldt L. Long-term oxygen therapy may improve skeletal muscle metabolism in advanced chronic obstructive pulmonary disease patients with chronic hypoxaemia. Respir Med 1995:89:471-6.

29 Engelen MP, Schols AM, Does JD, et al. Exercise-induced lactate increase in relation to muscle substrates in patients with chronic obstructive pulmonary disease. Am J Respir Crit Care Med 2000;162:1697-704.

30 Maltais $F$, LeBlanc $P$, Simard $C$, et al. Skeletal muscle adaptation to endurance training in patients with chronic obstructive pulmonary disease. Am J Respir Crit Care Med 1996;154:442-7.

31 Asada K, Sasaki S, Suda T, et al. Antiinflammatory roles of peroxisome proliferator-activated receptor gamma in human alveolar macrophages. Am J Respir Crit Care Med 2004;169:195-200.

32 Wigmore SJ, Fearon KC, Maingay JP, et al. Down-regulation of the acutephase response in patients with pancreatic cancer cachexia receiving oral eicosapentaenoic acid is mediated via suppression of interleukin-6. Clin Sci (Colch) 1997;92:215-21.

33 Fearon KC, Von Meyenfeldt MF, Moses AG, et al. Effect of a protein and energy dense N-3 fatty acid enriched oral supplement on loss of weight and lean tissue in cancer cachexia: a randomised double blind trial. Gut 2003:52:1479-86

34 Grimble RF, Howell WM, O'Reilly G, et al. The ability of fish oil to suppress tumor necrosis factor alpha production by peripheral blood mononuclear cells in healthy men is associated with polymorphisms in genes that influence tumor necrosis factor alpha production. Am J Clin Nutr 2002;76:454-9.

35 Broekhuizen R, Creutzberg EC, Weling-Scheepers CA, et al. Portion size rather than energy content of nutritional supplements enhances body weight gain in depleted COPD patients. Eur Respir J 2003;22:551-2s.

\section{LUNG ALERT}

Inhaled corticosteroids: no association with pregnancy induced hypertension in asthmatics

A Martel M-J, Rey E, Beauchesne M-F, et al. Use of inhaled corticosteroids during pregnancy and the risk of pregnancy induced hypertension: nested case control study. BMJ 2005;330:230-3

A sthma has been linked with an increased risk of pregnancy induced hypertension (PIHT), but it is unclear whether this association is due to medication or the condition itself. This nested case-control study selected a cohort of asthmatic pregnant women from 1990 to 2000 and identified 302 cases of PIHT from a total of 4593 pregnancies. Cases of PIHT were compared with suitably matched controls. In both groups the use and dosage of inhaled corticosteroids were analysed using two conditional logistic regression models. Use of inhaled corticosteroids during pregnancy was not associated with any increased risk of PIHT (adjusted OR 1.02, 95\% CI 0.77 to 1.34) or pre-eclampsia. In contrast, both oral corticosteroids and markers of uncontrolled/severe asthma were associated with a statistically significant increased risk of PIHT (oral corticosteroids: adjusted OR 1.57, 1.02 to 2.41). Markers of uncontrolled asthma included visits to the emergency department for asthma, use of oral corticosteroids, and having been reviewed by a respiratory specialist.

Asthma during pregnancy can result in potentially serious complications including PIHT. This study suggests that the use of inhaled corticosteroids for the control of asthma in pregnancy does not increase the risk of PIHT or pre-eclampsia. 